\title{
Trait-Mediated Indirect Effects of Phorid Flies on Ants
}

\author{
Hsun-Yi Hsieh and Ivette Perfecto \\ School of Natural Resources and Environment, University of Michigan, Ann Arbor, MI 48109, USA \\ Correspondence should be addressed to Hsun-Yi Hsieh, hhsieh@umich.edu
}

Received 25 December 2011; Accepted 9 February 2012

Academic Editor: Jean Paul Lachaud

Copyright ( $\odot 2012$ H.-Y. Hsieh and I. Perfecto. This is an open access article distributed under the Creative Commons Attribution License, which permits unrestricted use, distribution, and reproduction in any medium, provided the original work is properly cited.

This paper provides a synthesis of the ecological impact of phorid fly parasitoids on ants. We find the most important impact of phorids on ants to be trait-mediated effects. Phorids diminish the foraging activity of ants, frequently reducing the number and average size of foragers and reducing the amount of food retrieved by a colony. However, ants' coping mechanisms include changing foraging site and time. Phorids can also affect competition, especially through changes in the ability of the host to win in exploitative competition. Factors such as microclimate, resource size, and habitat complexity interact with phorids to change their effect on competition. By being highly specific and attacking ants high in the competitive hierarchy, phorids can alter the linear nature of the competitive transitivity, and by reducing the number of foragers, they can change the discovery-dominance tradeoff that is observed in some ant communities. Trait-mediated effects of phorids also cascade to other trophic levels. As an example, we discuss the trait-mediated cascade of phorids on the Azteca instabilis system in coffee. In this system, by reducing the foraging activity of $A$. instabilis, phorids reduce the direct and indirect biological control impact of the ant in the coffee agroecosystem.

\section{Introduction}

The best-studied family of ant parasitoids, Phoridae, has been recognized as an important mediator of ant community structure [1]. Indeed, over the past decades, there have been many studies on the impacts of phorid attacks on ants, from the effects on ant foraging activity, size of foragers, and amount of food retrieval, to the effects at the community level involving several interacting species at different trophic levels. What is clear from this literature is that the main consequences of phorid attacks on ants are not direct density effects but rather effects mediated by changes in the behavior of ants, the so-called trait-mediated indirect effects (TMIEs) [2]. Although many reviews have been written about TMIE generally [2-4], there has not been a review on how phorid flies impact ant communities through trait-mediated indirect interactions (TMIIs). Since phorid parasitoids attack mainly workers and parasitism rates tend to be very low, their direct impact on the colony is minor $[1,5]$. However, attacking phorid flies elicit ant defensive behaviors that can have repercussions at the community level. These trait-mediated effects have been shown to be important for understanding invasibility of ants [6] as well as the role of ants in biological control of agricultural pests [7].

In this paper we provide a synthesis of studies on the ecological impacts of phorids on ant assemblages and ecological networks focusing on TMII. The literature review focuses on studies published over the last ten years, since Feener's review [1]. However, we also use some of the older literature to support our conclusions. We first examine the effects of phorid parasitoids on ant foraging activity, including number of foragers, forager sizes, and amount of food retrieved. We then examine the evidence for the hypothesis that phorid parasitoids alter the outcome of competition among ants. More specifically, we examine evidence for the impact of phorid flies on exploitative and interference competition and for how parasitoids may alter competitive dominances among ant assemblages [1, 8-11]. Finally, we present evidence for trait-mediated effects that transcend ant assemblages and result in changes in the broader community including ant prey, ant mutualists, and 
the predators of the mutualists. For this last section, we focus on our own work of Azteca instabilis in coffee plantations.

\section{Direct Density Effects of Phorid Parasitization on Ants}

Studies examining direct mortality due to phorid parasitism on ants have reported very low parasitism rates. For example, Pseudacteon parasitism on Solenopsis geminata has been reported to be only 3\% [12], while Apocephalus parasitization on Pheidole has been reported to be $5 \%[13,14]$. Parasitization rates of ants in their introduced ranges can be even lower. Morrison and Porter [5] reported a 0.058\% of average parasitism rate per colony of Solenopsis invicta, a host ant species of Pseudacteon tricuspis Borgmeier in a time-span of two years study, in northern Florida. In his review, Feener [1] also indicated that the effects of densitymediated interaction between phorid parasitoids and host ants are normally very low, with $1-2 \%$ as the likely magnitude of the effect of direct phorid parasitism on host ant density reduction. Since most phorid flies that parasitize ants are highly host specific, use ant pheromones to find their host [15], and attack workers while foraging, retrieving food resources, or performing other tasks outside their nest, they are bound to elicit specialized defensive behavior that can result in TMIE [1]. Most of the research on the effects of phorid flies on ants has focused on these trait-mediated interactions between phorids and their ant hosts.

\section{Trait-Mediated Effects on Ant Foraging Activity, Resource Acquisition, and Defense}

3.1. Number of Foragers. One of the first recognized TMIE of phorids on ants was their effect on foraging activity [16]. Most ant colonies show behavioral responses to attacks by phorids. The most common behavioral response is a reduction in the number of foragers. Most of the studies show that the number of foragers or ants recruited to a resource is reduced significantly in the presence of phorids (Table 1) [16-37]. In the case of Azteca instabilis, this activity reduction results from two actions on the part of the individual workers. First, some ants go inside their nest, and second, some ants acquire a defensive posture and stop moving [7]. This defensive stationary posture has also been observed in S. geminata [21]. It has been shown that some species of Pseudacteon that parasitize A. instabilis and Solenopsis species require movement of the host in order to oviposit $[15,38]$. The combination of these two actions on the part of A. instabilis and S. geminata workers results in a reduction of $50 \%$ of the foraging activity in these two species $[21,30,31]$. Reductions in ant foraging activity in the presence of phorid flies have also been reported for Linepithema [32, 39], Pheidole [13, 14], and Atta [17, 40]. Ants can also respond to phorid attacks by increasing foraging activity during periods of time when phorids are not active, for example, at night. This seems to be the case for several species of the leaf cutter ants in the genus Atta
[16, 17, 26], for Linepithema [39], and for A. instabilis (de la Mora, unpublished data).

3.2. Size of Foragers. Phorid parasitoids also influence the size of foragers (Table 1). The pattern of worker size selection by ovipositing female phorid flies has been described for a few species of Pseudacteon on Solenopsis [12, 41-43], and Neodohrniphora on Atta [44, 45]. Mathis and Philpott [15] discuss ant size as a factor in host acceptance by phorid species. Differences in host size preferences within the fire ants are seen as an effective niche partitioning when several species attack the same host [36]. However, in general, phorid parasitoids tend to prefer larger than average workers. In these cases, the response of the ants to the presence of phorids is to reduce the average size of the foragers $[17,23$, 25-28, 40, 46, 47]. Morrison and Gilbert [43] reported that the size of the emergent phorid was positively related to the size of the host worker with females emerging from a larger host. If ant colonies respond to phorid attacks by changing the size distribution of foragers, this can alter the phorid's sex ratio and can potentially affect the efficiency of phorid parasitoids in biological control of invasive ants [43].

3.3. Acquisition of Food Resources. The reduction in the number and size of foragers can have an effect on the ability of ants to obtain and defend food resources [16, 17, 2228] (Table 1). Laboratory and field studies have reported up to $50 \%$ reduction in food acquisition by $S$. invicta in the presence of phorid flies [21, 23, 40]. In laboratory experiments, Mehdiabadi and Gilbert [22] showed that the presence of only one phorid fly per 200 workers of $S$. invicta reduced the number of large size workers 50 days later. In the same experiment, they demonstrated that the reduction in foraging and size of foraging workers resulted in a nearly twofold reduction of protein colony consumption. Reduction in the amount of food consumed in the presence of phorid flies has been reported for other ant genera including Linepithema [24] and Pheidole [20]. However, in another laboratory experiment with $S$. invicta and its Pseudacteon parasitoids, Morrison [23] showed that in control trials, where no phorids were present, food retrieval was intermediate to that of the phorid-no-phorid trials, suggesting that ants are foraging more in the nophorid trials (of the phorid-no-phorid trials) to compensate for the reduction in food retrieval from the phorid-present trials. This kind of compensation can happen in the field if the ants forage more during periods of no-phorid activity, as discussed previously, or shift to forage underground when phorids are present, something that has been shown to happen in Solenopsis [48]. Furthermore, in a laboratory experiment, Ramirez et al. [49] reported that reduction in food retrieval was not observed when the trials were left running for a period of 72 hours. These experiments suggest that in the long run and under field conditions ants that are attacked by phorid parasitoids compensate for potential losses in the amount of food retrieved by foraging more at times when phorids are not active. 
TABle 1: Ant response to phorid parasitism.

\begin{tabular}{|c|c|c|c|}
\hline \multicolumn{4}{|c|}{ Research retrieval } \\
\hline Ant spp. & Phorid spp. & Measured ant response to phorid parasitism & References \\
\hline Atta cephalotes & Neodohrniphora curvinervis & Reduced resource retrieval & {$[16]$} \\
\hline Atta sexdens & Neodohrniphora sp. & Reduced number of loaded ants & {$[17]$} \\
\hline Atta sexdens & Neodohrniphora sp. & Reduced resource retrieval & {$[18]$} \\
\hline Azteca instabilis & Pseudacteon sp. & $\begin{array}{l}\text { Increased time for foragers to carry away } \\
\text { resource }\end{array}$ & {$[19]$} \\
\hline Pheidole diversipilosa & Apocephalus sp. 8 & Increased resource turnover rate by competitor & {$[20]$} \\
\hline Solenopsis geminata & Pseudacteon browni and P. bifidus & Reduced resource retrieval & {$[21]$} \\
\hline Solenopsis invicta & Pseudacteon tricuspis & Reduced colony protein consumption & {$[22]$} \\
\hline Solenopsis invicta & Pseudacteon tricuspis & Reduced resource retrieval & {$[23]$} \\
\hline Solenopsis richteri & Pseudacteon sp. (multiple) & Reduced number of workers at resource & {$[24]$} \\
\hline \multicolumn{4}{|c|}{ Worker size } \\
\hline Ant spp. & Phorid spp. & Measured ant response to phorid parasitism & References \\
\hline Atta & Neodohrniphora erthali & Increased number of hitchhikers & {$[25]$} \\
\hline Atta cephalotes & Neodohrniphora curvinervis & Sent out workers in smaller size & {$[17]$} \\
\hline Atta cephalotes & Unreported & Sent out workers in smaller size & {$[26]$} \\
\hline Atta laevigata & Apocephalus attophilus & Sent out workers in smaller size & {$[27]$} \\
\hline Atta sexdens & Neodohrniphora sp. & Reduced forager mass & {$[17]$} \\
\hline Solenopsis invicta & Pseudacteon tricuspis & Sent out workers in smaller size & {$[22]$} \\
\hline Solenopsis invicta & Pseudacteon tricuspis & Sent out workers in smaller size & {$[23]$} \\
\hline Solenopsis invicta & Pseudacteon sp. & Altered ratio of worker size & {$[28]$} \\
\hline Solenopsis richteri & Pseudacteon sp. & Sent out workers in smaller size & {$[24]$} \\
\hline \multicolumn{4}{|c|}{ Ant activity } \\
\hline Ant spp. & Phorid spp. & Measured ant response to phorid parasitism & References \\
\hline Atta laevigata & Apocephalus attophilus & Altered number of foragers & {$[27]$} \\
\hline Atta sexdens & Myrmosicarius grandicornis & Reduced number of loaded ants & [29] \\
\hline Atta sexdens & Neodohrniphora sp. & $\begin{array}{l}\text { Increased number of unloaded workers } \\
\text { returning to nest \& decreased number of } \\
\text { loaded workers returning to nest }\end{array}$ & {$[17]$} \\
\hline Atta sexdens & Neodohrniphora sp. & Altered number of foragers & {$[17]$} \\
\hline Azteca instabilis & Pseudacteon sp. & Reduced ant activity & {$[30]$} \\
\hline Azteca instabilis & Pseudacteon sp. & Reduced number of ants & {$[31]$} \\
\hline Linepithema humile & Pseudacteon sp. & Altered number of foragers & {$[32]$} \\
\hline Pheidole titanis & Pseudacteon sp. & Reduced ant activity & {$[14]$} \\
\hline Solenopsis invicta & Pseudacteon tricuspis & Reduced number of exposed ants & {$[20]$} \\
\hline Solenopsis invicta & Pseudacteon tricuspis & Altered recruited ant size & {$[22]$} \\
\hline Solenopsis invicta & Pseudacteon tricuspis & Altered forager size & {$[34]$} \\
\hline Solenopsis invicta & Pseudacteon tricuspis & Reducers number of ants at baits & {$[23]$} \\
\hline Solenopsis invicta & Pseudacteon tricuspis & Reduced number of foragers & {$[35]$} \\
\hline Solenopsis invicta & Pseudacteon sp. & Reduced number of ants at baits & {$[28]$} \\
\hline Solenopsis richteri & Pseudacteon (multiple spp.) & Reduced number of ants at baits & {$[24]$} \\
\hline Solenopsis richteri & Pseudacteon (multiple spp.) & Reduced various ant activity & {$[24]$} \\
\hline Solenopsis saevissima & Pseudacteon sp. & Reduced ant activity & {$[36]$} \\
\hline Solenopsis sp. & Pseudacteon sp. & Altered number of foragers & {$[37]$} \\
\hline
\end{tabular}

3.4. Compensatory Factors. Other factors can help host species compensate for the negative trait-mediated effects of phorid parasitoids. For example, habitat complexity in the form of leaf litter provides refuge from parasitoids for soldier caste of Pheidole diversipilosa and P. bicarinata resulting in an increased number of foraging soldiers even in the presence of phorid parasitoids [50]. Habitat complexity, thus, allows these two species to balance foraging success with the 
avoidance of parasitism. Likewise, the size and distribution of resources can have similar effects. In a field experiment, Wilkinson and Feener [51] demonstrated that the presence of multiple large resources allows colonies of $P$. diversipilosa to redistribute soldier ants from sites that have phorid flies to sites that do not have phorids, therefore maintaining overall numbers of foraging soldiers at the same levels as found in the absence of phorid parasitoids.

There is a gap in our knowledge about how many ant hosts mitigate the threat of phorid parasitism by altering regimes, altering posture of exposure, or by foraging on other resources. It is possible that we may be overestimating the population level impact of phorid parasitoids on ants by focusing on day time interactions or by not measuring other population level parameters such as density, occupancy, and colony migration.

\section{Phorid Parasitoids and Competition within Ant Assemblages}

The kinds of behavioral changes described in the previous section can have important consequences for ant community structure. Since phorid parasitoids tend to be highly specific and attack only one or very few species of ants within a community, they can alter the competitive interactions and change ant community structure [1]. This effect can be especially important when the host ant is a competitive dominant species, which in the best-studied cases of ant-phorid interactions they frequently are, probably because dominant ant species are evolutionarily more conspicuous [1].

When phorid parasitoids are present, host species are faced with a tradeoff between defending themselves against parasitism and maximizing their competitive abilities. The outcome of this tradeoff is not always clear. Based on the evidence of the TMIE of phorid parasitoids on host ants, it is tempting to conclude that phorid parasitoids reduce the competitive ability of host species. However, this is not always the case. Indeed, competitive interactions among ants are complex and influenced by a variety of factors, and therefore, a generalized outcome of the effects of phorid parasitoids on ant competitive interactions is highly unlikely. What we see in the literature is a reflection of that complexity.

4.1. Exploitative and Interference Competition. Ants of different species engage in exploitative and interference competition with each other $[20,21,34,52-54]$. Exploitative competition occurs when the removal of a limiting resource by one species makes it unavailable for other species, while interference competition involves direct aggressive interactions between individuals of different species. The presence of phorid parasitoids has been shown to influence both of these types of competition but this is, in no way, a universal phenomenon. For example, in laboratory experiments, phorid parasitoids were found to increase the exploitative competitive ability of Forelius mccooki, a competitor of the host species, S. invicta. However, phorids did not affect the direct aggressive interactions between the two species [34]. Furthermore, although the competitor of the host species increased the number of foragers by a factor of two in the presence of phorid flies, that did not translate into higher colony growth. Similar results have been reported in field experiments. A study of the competitive interactions between S. geminata and S. invicta in the presence of phorid parasitoids of $S$. geminata found that the host species retrieved 50\% less food than the nonhost species in the presence of phorid flies [21]. Much the same as in the lab experiment, in the field, phorid parasitoids had no effect on the interspecific aggression between S. geminata and $S$. invicta and did not affect the outcome of these interactions at resources. In the case of $A$. instabilis, phorids also seem to influence exploitative but not interference competition $[31,55]$. In field experiments, competitors of $A$. instabilis were able to access bait resources 12 times more often in the presence of phorids and were able to take over baits only when phorid parasitoids of $A$. instabilis were present. However, in most cases, $A$. instabilis did not lose competitive interactions with other species [55]. The lack of an effect in the interference competition interactions between host and nonhost species could be due to the behavioral response of the ants engaged in the fight or a change in behavior of the phorid parasitoids. For example, S. geminata has been seen to ignore attacking phorids when engaged in fights with $S$. invicta [21]. But, phorid parasitoids have also been observed to lose interest or be distracted by ants that are engaged in active fighting with other ants. Feener [13] presented the first evidence for the TMIE of phorids on interference competition between the host species Pheidole dentata and its competitor, Diplorhoptrum texanum (referred to as Solenopsis texana). It is reported that parasitism by phorids was the factor that most strongly influenced the turnover of resources from $P$. diversipilosa to its competitors [20]. The same study also reports that phorid parasitoids reduce exploitative competitive abilities of $P$. diversipilosa [20]. On the other hand, Orr et al. [53] report that phorid parasitoids seldom influence exploitative competition between two Linepithema species and their nonhost competitors in Brazil. This field study joins others that have not been able to detect clear effects of phorids on ant competition [56].

4.2. Factors That Interact with Phorid Parasitoids to Affect Competition. The lack of a clear pattern on the effect of phorid's TMIE on ant competition has to do with the many other factors that are involved in determining the winners and losers of both exploitative and interference competition. Among the potential factors, here we will discuss four, for which there is some evidence in the literature: feedback loops caused by ant chemical pheromones, size and distribution of resources, habitat complexity, and abiotic factors such as temperature and humidity.

Phorid flies are known to use ant kairomones released by their host ant to locate them [15]. When an ant encounters a competitor, it is more likely to release alarm pheromones that can be used by their phorid parasitoids to find them more easily, causing a positive feedback that may result in a higher turnover rate of resources from host species to their competitors [20]. There are at least two cases where these 
kinds of positive feedbacks have been documented. The parasitoid Apocephalus sp. discovers faster and arrives in greater numbers at recruitment events where its host species, $P$. diversipilosa, is engaged in competitive conflict than to recruitment events where the host is foraging alone or does not experience conflict [20]. Likewise, parasitoids of two species of Linepithema arrived significantly faster at resources where the host was with another ant species than when it was alone [39]. Furthermore, the rate at which phorid flies arrive at baits depends on the competitor species present and the type of response it elicits from Linepithema. Phorid parasitoids arrived faster at baits when the competitor elicits a chemical response versus baits where the competitor elicits primarily physical aggression [39]. If host ants engaged in direct competition with other species elicit faster and stronger responses from their phorid parasitoids than those that do not encounter competitors, phorids can have an even stronger effect on competition through this positive feedback. Moreover, if the feedback mechanism works for some competitors and not others, as in the case of Linepithema and its competitors, the impact of phorids on community structure and colony energetic will depend on these behavioral responses and will be different in different community contexts.

The effects of resource size and distribution and habitat complexity were discussed in the previous section in the context of compensation mechanisms for acquiring resources under the pressure of phorid attacks. These factors can also buffer the impacts of phorids on competitive interactions between host species and nonhost species [10, $20,50,51]$. For example, habitat complexity, by allowing continued foraging even when phorids are present, can influence the competitive success of the host species [50]. Likewise, widely distributed resources may allow host species to redistribute their foragers to resources not monitored by phorids and continue succeeding in exploitative competition [51]. Recruitment to large resources, on the other hand, could increase the number of phorid attacks but the effect of resource size has not been well explored in the literature. In general, ants that recruit to resources tend to recruit more and larger workers to larger resources $[20,24]$. Since phorid parasitoids show a density-dependent response to ants $[55,57]$, higher numbers of ants at a resource will attract higher numbers of phorid parasitoids. Therefore, a higher proportion of large resources at a particular site could represent a liability for those host species that recruit to large resources, which is the case for most species attacked by phorids. However, if a higher proportion of larger resources also results in greater availability of large resources to hosts, ant hosts would be able to switch to resources not monitored by parasitoids [50].

Temperature and humidity affect not only ants but also phorids [58-61]. These two variables could interact to lead to very different competitive outcomes under varying environmental conditions. For example, parasitoid habitat preferences (see [15]) have been shown to cause major differences on parasitism pressure on host ants and their interactions with competitors [11]. In laboratory experiments, Ramirez et al. [49] demonstrated that changes in humidity interact with the presence of phorid parasitoids to alter the competitive outcome of encounters between the invasive $S$. invicta and the native species $S$. xyloni. They attributed the lack of establishment and spread of $S$. invicta in New Mexico to these interactions.

\subsection{Competitive Dominance Hierarchies and Species Coexis-} tence. Interspecific competition can have profound effects on the abundance, composition, and distribution of species. Communities structured by competition can be organized in a variety of ways that can greatly influence species coexistence and, therefore, the maintenance of diversity within a community. Competitive communities that are organized in a linear transitive dominance hierarchy will tend to have low species diversity because, at equilibrium, the competitive dominant species will exclude all others. On the other hand, intransitive hierarchies, a situation in which the competing species cannot be ranked in a perfect competitive hierarchy, can promote diversity [62-67]. Interspecific competition has been identified as an important factor in structuring ant communities, especially among ground foraging omnivorous ants that forage more or less for the same resources $[52,68-76]$. However, to date, no competitive intransitivity has been convincingly demonstrated for any ant community. Rather, ant communities have been described to be organized in transitive dominance hierarchies $[10,11,52,69,77,78]$. A question then emerges as to how ant communities are able to maintain species diversity under conditions of transitive dominant hierarchies. TMIE mediated by phorid parasitoids can provide a partial answer to this question $[10,13,20]$, although other factors such as environmental variation [56, $75,79]$ and size of resources [10, 51, 80, 81] have called into question the generality of the transitive dominance hierarchies among ant communities.

By being highly specific and attacking ants that tend to be high in the competitive hierarchy, phorids can alter the linear nature of the competitive transitivity. In a study of the ant community in pine-oak woodlands in Arizona, LeBrun [10] describes several distinct dominance hierarchies within the ant assemblage. However, the linearity of the dominance hierarchies was determined by the size of the resource and the presence of phorid parasitoids. When competing for fixed resources or for small nonfixed resources in the absence of phorids, the assemblage exhibits significant linear dominance hierarchies. In contrast, in the presence of phorids for both fixed and small resources, this linearity breaks down [10]. For example, on fixed resources, phorids caused the second dominant species to drop to the second most subordinate, and the third species dropped to the forth position. These changes in the ranking of species dominance generated more indeterminacy in the outcome of individual paired interactions reducing the asymmetries underlying the dominance in the transitive hierarchy. It has been shown, at least theoretically, that when interactions take place locally, which is the case for ants competing for food resources, an increase in symmetry favors diversity [66], providing a potential mechanism for the maintenance of diversity in ant communities. 
An alternative competitive structure to the dominant hierarchy that has been described for ant assemblages is the so-called dominance-discovery tradeoff $[11,68,69$, $72,82-87]$. The tradeoff implies that while some species are good at dominating resources, others are good at discovering the resource $[54,69,74,83,85]$. This tradeoff can also lead to species coexistence in much the same way that the competition-colonization tradeoff [88] and the virulence-transmission tradeoff [89] lead to species coexistence $[10,90]$. Phorid-induced TMIE can play an important role in maintaining species within the dominancediscovery tradeoff curve, therefore promoting diversity [85]. For example, examining the same ant assemblage in pineoak woodlands in Arizona, LeBrun and Feener found that the elimination of phorid parasitoids caused host species to become too dominant for their level of discovery ability, breaking down the dominance-discovery tradeoff. It has been proposed that this could be a mechanism for the spread of invasive ant species in areas where they are released from parasitoid pressure $[1,85]$. However, examining the competitive interactions among an assemblage of ground foraging ants and S. invicta in its native range, Feener et al. [11] did not find strong support for this hypothesis. Rather, they proposed that both interspecific competition and TMIE of phorid parasitoids affect the success of S. invicta in its native range, but that these factors vary dramatically in different regions.

Overall, these studies suggest that phorid parasitoids can have a strong effect on competitive interactions within ant assemblages but these effects are, in no way, consistent and are mediated by many other factors that vary in time and space, such as microclimate, habitat heterogeneity, and size and abundance of resources.

\section{Trait-Mediated Cascades: The Case of Azteca instabilis in the Coffee Agroecosystem}

Ants are an important component of ecosystems in most regions of the world. Since they frequently constitute a great part of the animal biomass in ecosystems, are taxonomically diverse, and act as ecosystem engineers [91-93], they tend to interact with many other organisms. Given the strong TMIE of phorids on ants, and given the wide range of ecological interactions that ants form with other organisms, it should come as no surprise that these TMIEs cascade into other trophic levels of an ecological community. The best-documented case of these sorts of phorid-mediated cascading effects can be found in the A. instabilis system. For more than ten years, we have been studying the ecological interactions surrounding this ant species in coffee plantations in southern Mexico (for a review see [7]). Here we will describe the pivotal role that phorid parasitoids play in shaping these interactions.

Azteca instabilis is a dominant arboreal ant with a wide distribution in the Americas, from Brazil to Mexico [94]. On coffee plantations it is found nesting in shade trees and foraging on both shade trees and coffee plants. This species forms spatial clusters of nests that have a high genetic relatedness (Remfert, unpublished data). The clusters appear to be the result of self-organization emerging from the internal dynamics of the system - short distance dispersal to adjacent trees and density-dependent mortality [95]. One of the main resources for $A$. instabilis in the coffee plantations is honeydew from Coccus viridis, the green coffee scale [96]. This mutualism plays an essential role in the distribution of the scale insect, which is a potential pest in coffee [96]. Azteca instabilis has been reported to prey on a variety of herbivores in coffee plantations contributing to the control of potential insects pests $[7,19,96-100]$. The effect of $A$. instabilis on deterring herbivores is not only through the direct action of preying or removing herbivores from plants, but also through an indirect effect in which some herbivores avoid plants that have been foraged on by A. instabilis, but were no actual ants where present when the herbivores arrive [99]. Additionally, it has been shown that through a complex network of ecological interactions A. instabilis is a keystone species that contributes to the regulation of insect pests and diseases in coffee $[7,101-103]$. Azteca instabilis also competes with other arboreal ant species, especially twignesting species [104], and influences the abundance and diversity of ground nesting and arboreal ant species (Perfecto and Vandermeer, in review; Ennis, unpublished data) and spiders (Marin, unpublished data). The mutualism between A. instabilis and the scale insects consists of protection of scales from parasitoids and predators, especially the coccinellid beetle, Azya orbigera [30, 101], and removal of sooty mold (Jha et al., in review).

Philpott et al. [19] published the first documented case of a phorid parasitoid attacking A. instabilis. At that time it was thought that only one species of Pseudacteon was responsible for the attacks. However, recently (see [105] in this issue) three species have been described attacking $A$. instabilis. Pseudacteon spp. have strong TMIE on A. instabilis $[19,31,55]$, as reported previously. More importantly, these TMIEs cascade to other trophic levels within the community, with important implications for the biological control of insect herbivores and diseases of coffee $[7,101]$.

By reducing A. instabilis foraging activity, phorids disrupt the ability of the ants to remove insect pests from coffee [19]. In laboratory experiments, it was shown that phorids essentially cancel the ability of $A$. instabilis to deter coffee berry borer attacks on coffee fruits [100]. Likewise, we have demonstrated that the presence of phorids reduces the ability of ants to attack, carry away, and force off plants lepidopteran caterpillars that could be potential pests in coffee [19].

Higher-order cascading trait-mediated indirect effects have also been documented for this system $[7,30,101]$. The protection that the ants offer to their scale mutualist is the first level trait-mediated indirect effect-the ants disrupt the ability of the predatory beetle to kill and consume scale insects. By causing a reduction in the foraging activity of $A$. instabilis, phorids disrupt the ability of the ant to protect its mutualist, the green coffee scale [30]. This is the second order trait mediated indirect effect (Figure 1). When phorids are present, they essentially cancel the protective effect of ants against adults of A. orbigera, the coccinellid predator. In laboratory experiments, in the presence of ants and phorids 


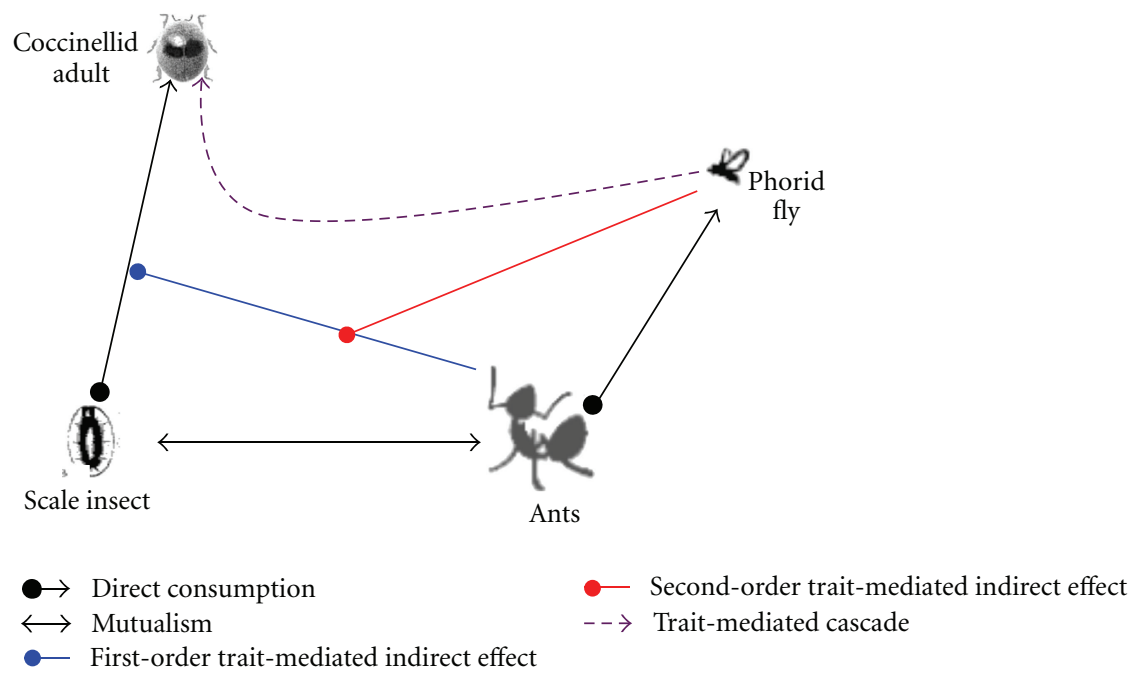

Figure 1: Diagrammatic representation of the cascading trait-mediated indirect interactions between Pseudacteon spp. and Azya orbigera. Arrows represent positive effects and solid circles represent negative effects. Black solid lines represent direct interactions, the blue solid line represents first level trait-mediated indirect interactions, the red solid lines represents the second level trait-mediated indirect interactions, and the dashed purple line represents the resulting cascading trait-mediated indirect interaction between the phorid flies and the coccinellid beetle.

adults of the predatory beetle were able to gain access to the scale and consume the same quantities as when no ants (and no phorids) were present. In other words, through these higher order cascading trait mediated indirect effects, the phorids facilitate the coccinellid beetle (Figure 1).

The complexity of this network of interactions increases when the larval stage of the coccinellid beetle is considered. The larva of $A$. orbigera is covered by waxy filaments that protects it from ant predation [106]. This means that larvae of the main predator of the scales are able to live in patches of high ant activity where the scale is abundant. Furthermore, the ants repel parasitoids in the vicinity of the scale insects, including any parasitoids of the coccinellid beetle, essentially protecting coccinellid larvae [106]. The presence of phorids could, potentially, eliminate this unintended protective effect of the ants on the coccinellid larvae, by reducing ant patrolling on clusters of scales. However, this interaction has not been yet documented.

Our research also shows that gravid female beetles of A. orbigera are able to eavesdrop on the "phorid-alert pheromones" (Hsieh, unpublished data) and oviposit under green coffee scales or other clandestine microsites that workers of $A$. instabilis and natural enemies of $A$. orbigera would have difficulty finding, removing, and predating. The natural history and interactions between Pseudacteon spp., $A$. instabilis, and A. orbigera can well explain why we can find high abundances of A. orbigera in the coffee agroecosystem. Since this is the main predator of the green coffee-scale, and it seems to require patches of $A$. instabilis for the successful development of its larvae, it can be argued that the maintenance of the Azteca-green coffee scale mutualism is essential for the successful biological control of the green scale at the level of the entire farm [7, 95].
Theoretically and empirically, parasitism in spatially distinct patches has been suggested to be an important driver of spatial self-organization of host-parasitoid dynamics [107]. The Azteca system in the coffee agroecosystem adds empirical evidence to the theory of spatial self-organization in host-parasitoid systems. We proposed that Pseudacteon spp. contributes to the spatial pattern formation of $A$. instabilis by acting as a density-dependent control mechanism [95]. Given the fact that the coccinellid beetle is able to capitalize on the trait mediated interaction between Pseudacteon spp. and A. instabilis, we suggest that adding trait-mediated cascades to theoretical models would increase our understanding of how complex systems might contribute to spatial self-organization and system stability. Furthermore, the $A$. instabilis-Pseudacteon spp.-A. orbigera system illustrates how trait-mediated cascades effect biological control in a spatially explicit complex ecosystems.

\section{Conclusion}

Phorid fly parasitoids influence ants mainly through traitmediated indirect interactions. The presence of phorid flies results in a reduction of foragers, a change in the average size of foragers, mainly toward the smaller sizes, shifts in the time and places of foraging to avoid encounters with phorids, and reduction in the amount of food retrieved. These effects, independently or in combination, have important consequences for the way ants interact with other ant species and with other members of the interacting network within a community.

Through these TMIEs phorids can have important effects on competitive interactions among ants. When phorid parasitoids are present, host species respond behaviorally and 
can impact their competitive abilities. However, since competitive interactions among ants are complex and influenced by a variety of factors, the outcome of the effects of phorid parasitoids on ant competitive interactions is highly variable. Phorids have been shown to reduce exploitative competitive abilities of some host species but not others. Likewise, they have been shown to affect the interference competition between host and nonhost, but this effect is not widespread among studies. It has been shown that phorid parasitoids can break a competitive hierarchy within ant assemblages by attacking the most competitive dominant species within the hierarchy. Phorids also can influence the dominancediscovery tradeoff that is found in some ant assemblages. The alteration of the competitive structure of ant assemblages could be important in understanding invasibility of ants to ranges where their phorid parasitoids are absent.

Trait-mediated effects of phorids on ants can also transcend the ant assemblage and have cascading effects on other trophic levels and other organisms linked to the host ant species through complex ecological networks. For example, phorid parasitoids can also influence the impact of ants on herbivores. If the host species is an important predator of an herbivore, the presence of phorids can release these herbivores from predation pressure from ants. This could be important in agroecosystems where ants have been shown to be important predators of insect pests. The study of $A$. instabilis in coffee plantations presents an excellent case study of these cascading trait-mediated indirect interactions and shows that they could be important in maintaining biological control.

Many areas of research remain open in the study of ant-phorid interactions. In particular there are very few studies that link TMIEs of phorids to population level consequences in ants and other organisms. Making and testing predictions regarding the TMIEs of phorids on population density, occupancy, colonization, and migration patterns across landscapes should be priority of future studies. The Azteca system described previously represents a step in the right direction to fill this gap in our knowledge of ant-phorid interactions. However, this system is only one example of the many complex ecological networks that could be influenced by phorid parasitoids. Future studies should focus on these kinds of complex ecological networks and on trait-mediated cascading effects that would be important in understanding the role of ants when they are embedded in complex ecological networks.

\section{Acknowledgments}

The authors thank J. Vandermeer and Stacy Philpott for comments on an earlier version of the manuscript.

\section{References}

[1] D. H. Feener Jr., "Is the assembly of ant communities mediated by parasitoids?" Oikos, vol. 90, no. 1, pp. 79-88, 2000.

[2] E. E. Werner and S. D. Peacor, "A review of trait-mediated indirect interactions in ecological communities," Ecology, vol. 84, no. 5, pp. 1083-1100, 2003.
[3] O. J. Schmitz, V. Krivan, and O. Ovadia, "Trophic cascades: the primacy of trait-mediated indirect interactions," Ecology Letters, vol. 7, no. 2, pp. 153-163, 2004.

[4] B. Bolker, M. Holyoak, V. Krivan, L. Rowe, and O. Schmitz, "Connecting theoretical and empirical studies of traitmediated interactions," Ecology, vol. 84, no. 5, pp. 1101-1114, 2003.

[5] L. W. Morrison and S. D. Porter, "Testing for populationlevel impacts of introduced Pseudacteon tricuspis flies, phorid parasitoids of Solenopsis invicta fire ants," Biological Control, vol. 33, no. 1, pp. 9-19, 2005.

[6] J. A. Briano, L. Calcaterra, and L. Varone, "Fire ants (Solenopsis spp.) and their natural enemies in Southern South America," Psyche, vol. 2012, Article ID 198084, 19 pages, 2012.

[7] J. Vandermeer, I. Perfecto, and S. M. Philpott, "Ecological complexity and pest control in organic coffee production: uncovering an autonomous ecosystem service," Bioscience, vol. 60, no. 7, pp. 527-537, 2010.

[8] S. D. Porter and D. A. Savignano, "Invasion of polygyne fire ants decimates native ants and disrupts arthropod community," Ecology, vol. 71, no. 6, pp. 2095-2106, 1990.

[9] M. R. Orr, S. H. Seike, W. W. Benson, and L. E. Gilbert, "Flies suppress fire ants," Nature, vol. 373, no. 6512, pp. 292-293, 1995.

[10] E. G. LeBrun, "Who is the top dog in ant communities? Resources, parasitoids, and multiple competitive hierarchies," Oecologia, vol. 142, no. 4, pp. 643-652, 2005.

[11] D. H. Feener, M. R. Orr, K. M. Wackford, J. M. Longo, W. W. Benson, and L. E. Gilbert, "Geographic variation in resource dominance discovery in Brazilian ant communities," Ecology, vol. 89, no. 7, pp. 1824-1836, 2008.

[12] L. W. Morrison, C. G. Dall'aglio-Holvorcem, and L. E. Gilbert, "Oviposition behavior and development of Pseudacteon flies (Diptera: Phoridae), parasitoids of Solenopsis fire ants (Hymenoptera: Formicidae)," Environmental Entomology, vol. 26, no. 3, pp. 716-724, 1997.

[13] D. H. Feener Jr., "Competition between ant species: outcome controlled by parasitic flies," Science, vol. 214, no. 4522, pp. 815-817, 1981.

[14] D. H. Feener Jr., "Effects of parasites on foraging and defense behavior of a termitophagous ant, Pheidole titanis Wheeler (Hymenoptera: Formicidae)," Behavioral Ecology and Sociobiology, vol. 22, no. 6, pp. 421-427, 1988.

[15] K. A. Mathis and S. M. Phillpott, "Current understanding of future prospects of host selection, acceptance, discrimination, and regulation of phorid fly parasitoids that attack ants," Psyche, vol. 2012, Article ID 895424, 9 pages, 2012.

[16] M. R. Orr, "Parasitic flies (Diptera: Phoridae) influence foraging rhythms and caste division of labor in the leaf-cutter ant, Atta cephalotes (Hymenoptera: Formicidae)," Behavioral Ecology and Sociobiology, vol. 30, no. 6, pp. 395-402, 1992.

[17] M. A. L. Bragança, A. Tonhasca Jr., and T. M. C. Delia Lucia, "Reduction in the foraging activity of the leaf-cutting ant Atta sexdens caused by the phorid Neodohrniphora sp.", Entomologia Experimentalis et Applicata, vol. 89, no. 3, pp. 305-311, 1998.

[18] A. Tonhasca Jr. and M. A. L. Bragança, "Effect of leaf toughness on the susceptibility of the leaf-cutting ant Atta sexdens to attacks of a phorid parasitoid," Insectes Sociaux, vol. 47, no. 3, pp. 220-222, 2000.

[19] S. M. Philpott, J. Maldonado, J. Vandermeer, and I. Perfecto, "Taking trophic cascades up a level: behaviorally-modified 
effects of phorid flies on ants and ant prey in coffee agroecosystems," Oikos, vol. 105, no. 1, pp. 141-147, 2004.

[20] E. G. LeBrun and D. H. Feener Jr., "Linked indirect effects in ant-phorid interactions: impacts on ant assemblage structure," Oecologia, vol. 133, no. 4, pp. 599-607, 2002.

[21] L. W. Morrison, "Indirect effects of phorid fly parasitoids on the mechanisms of interspecific competition among ants," Oecologia, vol. 121, no. 1, pp. 113-122, 1999.

[22] N. J. Mehdiabadi and L. E. Gilbert, "Colony-level impacts of parasitoid flies on fire ants," Proceedings of the Royal Society B, vol. 269, no. 1501, pp. 1695-1699, 2002.

[23] L. W. Morrison, "Mechanisms of Pseudacteon parasitoid (Diptera: Phoridae) effects on exploitative and interference competition in host Solenopsis ants (Hymenoptera: Formicidae)," Annals of the Entomological Society of America, vol. 93, no. 4, pp. 841-849, 2000.

[24] P. J. Folgarait and L. E. Gilbert, "Phorid parasitoids affect foraging activity of Solenopsis richteri under different availability of food in Argentina," Ecological Entomology, vol. 24, no. 2, pp. 163-173, 1999.

[25] E. H. M. Vieira-Neto, F. M. Mundim, and H. L. Vasconcelos, "Hitchhiking behaviour in leaf-cutter ants: an experimental evaluation of three hypotheses," Insectes Sociaux, vol. 53, no. 3, pp. 326-332, 2006.

[26] C. B. Yackulic and O. T. Lewis, "Temporal variation in foraging activity and efficiency and the role of hitchhiking behaviour in the leaf-cutting ant, Atta cephalotes," Entomologia Experimentalis et Applicata, vol. 125, no. 2, pp. 125-134, 2007.

[27] M. Erthal Jr. and A. Tonhasca Jr., "Biology and oviposition behavior of the phorid Apocephalus attophilus and the response of its host, the leaf-cutting ant Atta laevigata," Entomologia Experimentalis et Applicata, vol. 95, no. 1, pp. 71-75, 2000.

[28] R. T. Puckett and M. K. Harris, "Phorid flies, Pseudacteon spp. (Diptera: Phoridae), affect forager size ratios of red imported fire ants Solenopsis invicta (Hymenoptera: Formicidae) in Texas," Environmental Entomology, vol. 39, no. 5, pp. 15931600, 2010.

[29] A. Tonhasca Jr., M. A. L. Bragança, and M. Erthal Jr., "Parasitism and biology of Myrmosicarius grandicornis (Diptera, Phoridae) in relationship to its host, the leaf-cutting ant Atta sexdens (Hymenoptera, Formicidae)," Insectes Sociaux, vol. 48, no. 2, pp. 154-158, 2001.

[30] H. Liere and A. Larsen, "Cascading trait-mediation: disruption of a trait-mediated mutualism by parasite-induced behavioral modification," Oikos, vol. 119, no. 9, pp. 13941400, 2010.

[31] S. M. Philpott, "Trait-mediated effects of parasitic phorid flies (Diptera: Phoridae) on ant (Hymenoptera: Formicidae) competition and resource access in coffee agro-ecosystems," Environmental Entomology, vol. 34, no. 5, pp. 1089-1094, 2005.

[32] M. R. Orr and S. H. Seike, "Parasitoids deter foraging by Argentine ants (Linepithema humile) in their native habitat in Brazil," Oecologia, vol. 117, no. 3, pp. 420-425, 1998.

[33] M. A. L. Bragança, L. M. de Souza, C. A. Nogueira, and T. M. C. Della Lucia, "Parasitism by Neodohrniphora spp. Malloch (Diptera, Phoridae) on workers of Atta sexdens riblopilosa Forel (Hymenoptera, Formicidae)," Revista Brasileira de Entomologia, vol. 52, no. 2, pp. 300-302, 2008.

[34] N. J. Mehdiabadi, E. A. Kawazoe, and L. E. Gilbert, "Phorid fly parasitoids of invasive fire ants indirectly improve the competitive ability of a native ant," Ecological Entomology, vol. 29, no. 5, pp. 621-627, 2004.

[35] J. L. Mottern, K. M. Heinz, and P. J. Ode, "Evaluating biological control of fire ants using phorid flies: effects on competitive interactions," Biological Control, vol. 30, no. 3, pp. 566-583, 2004.

[36] M. R. Orr, S. H. Seike, and L. E. Gilbert, "Foraging ecology and patterns of diversification in dipteran parasitoids of fire ants in South Brazil," Ecological Entomology, vol. 22, no. 3, pp. 305-314, 1997.

[37] S. D. Porter, R. K. Vander Meer, M. A. Pesquero, S. Campiolo, and H. G. Fowler, "Solenopsis (Hymenoptera: Formicidae) fire ant reactions to attacks of Pseudacteon flies (Diptera: Phoridae) in South Eastern Brazil," Annals of the Entomological Society of America, vol. 88, no. 4, pp. 570-575, 1995.

[38] K. A. Mathis, S. M. Philpott, and R. F. Moreira, "Parasite lost: chemical and visual cues used by Pseudacteon in search of Azteca instabilis," Journal of Insect Behavior, vol. 24, no. 3, pp. 186-199, 2011.

[39] M. R. Orr, D. L. Dahlsten, and W. W. Benson, "Ecological interactions among ants in the genus Linepithema, their phorid parasitoids, and ant competitors," Ecological Entomology, vol. 28, no. 2, pp. 203-210, 2003.

[40] A. Tonhasca Jr., "Interaction between a parasitic fly, Neodohrniphora declinata (Diptera: Phoridae), and its host, the leaf-cutting ant Atta sexdens rubropolosa (Hymenoptera: Formicidae)," Ecotropica, vol. 2, pp. 157-164, 1996.

[41] D. H. Feener Jr., "Size-selective oviposition in Pseudacteon crawfordi (Diptera: Phoridae), a parasite of fire ants," Annals of the Entomological Society of America, vol. 80, no. 2, pp. 148151, 1987.

[42] S. Campiolo, M. A. Pesquero, and H. G. Fowler, "Sizeselective oviposition by phorid (Diptera: Phoridae) parasitoids on workers of the fire ant, Solenopsis saevissima (Hymenoptera: Formicidae)," Etologia, vol. 4, pp. 85-86, 1994.

[43] L. W. Morrison and L. E. Gilbert, "Parasitoid-host relationships when host size varies: the case of Pseudacteon flies and Solenopsis fire ants," Ecological Entomology, vol. 23, no. 4, pp. 409-416, 1998.

[44] V. S. G. Silva, O. Bailez, A. M. Viana-Bailez, A. Tonhasca Jr., and T. M. Castro Della Lucia, "Survey of Neodohrniphora spp. (Diptera: Phoridae) at colonies of Atta sexdens rubropilosa (FOREL) and specificity of attack behaviour in relation to their hosts," Bulletin of Entomological Research, vol. 98, no. 2, pp. 203-206, 2008.

[45] M. A. L. Bragança, A. Tonhasca Jr., and T. M. C. Della Lucia, "Características biológicas e comportamentais de Neodohrniphora elongata Brown (Diptera, Phoridae), um parasitóide da saúva Atta sexdens rubropilosa Forel (Hymenoptera, Formicidae)," Revista Brasileira de Entomologia, vol. 53, no. 4, pp. 600-606, 2009.

[46] D. H. Feener Jr. and B. V. Brown, "Reduced foraging of Solenopsis geminata (Hymenoptera: Formicidae) in the presence of parasitic Pseudacteon spp. (Diptera: Phoridae)," Annals of the Entomological Society of America, vol. 85, no. 1, pp. 80-84, 1992.

[47] D. H. Feener Jnr Jr. and B. V. Brown, "Oviposition behavior of an ant-parasitizing fly, Neodohrniphora curvinervis (Diptera: Phoridae), and defense behavior by its leaf-cutting ant host Atta cephalotes (Hymenoptera: Formicidae)," Journal of Insect Behavior, vol. 6, no. 6, pp. 675-688, 1993. 
[48] L. E. Tennant and S. D. Porter, "Comparison of diets of two fire ant species (Hymenoptera: Formicidae): solid and liquid components," Entomological Sciences, vol. 26, pp. 450-465, 1991.

[49] R. A. Ramirez II, D. C. Thompson, and M. D. Remmenga, "Influence of low humidity, Pseudacteon flies (Diptera: Phoridae), and competition by Solenopsis xyloni on Solenopsis invicta (Hymenoptera: Formicidae)," Environmental Entomology, vol. 35, no. 4, pp. 1037-1048, 2006.

[50] E. B. Wilkinson and D. H. Feener Jr., "Habitat complexity modifies ant-parasitoid interactions: implications for community dynamics and the role of disturbance," Oecologia, vol. 152, no. 1, pp. 151-161, 2007.

[51] E. B. Wilkinson and D. H. Feener Jr., "Variation in resource size distribution around colonies changes ant-parasitoid interactions," Insectes Sociaux, vol. 57, no. 4, pp. 385-391, 2010.

[52] R. Savolainen and K. Vepsäläinen, "A competition hierarchy among boreal ants: impact on resource partitioning and community structure," Oikos, vol. 51, no. 2, pp. 135-155, 1988.

[53] M. R. Orr, R. X. de Camargo, and W. W. Benson, "Interactions between ant species increase arrival rates of an ant parasitoid," Animal Behaviour, vol. 65, no. 6, pp. 1187-1193, 2003.

[54] I. Perfecto and J. Vandermeer, "Discovery dominance tradeoff: the case of Pheidole subarmata and Solenopsis geminata (Hymenoptera: Formicidae) in neotropical pastures," Environmental Entomology, vol. 40, no. 5, pp. 999-1006, 2011.

[55] S. M. Philpqtt, I. Perfecto, J. Vandermeer, and S. Uno, "Spatial scale and density dependence in a host parasitoid system: an arboreal ant, Azteca instabilis, and its Pseudacteon phorid parasitoid," Environmental Entomology, vol. 38, no. 3, pp. 790-796, 2009.

[56] L. W. Morrison, E. A. Kawazoe, R. Guerra, and L. E. Gilbert, "Ecological interactions of Pseudacteon parasitoids and Solenopsis ant hosts: environmental correlates of activity and effects on competitive hierarchies," Ecological Entomology, vol. 25, no. 4, pp. 433-444, 2000.

[57] D. C. Henne and S. J. Johnson, "Laboratory evaluation of aggregation, direct mutual interference, and functional response characteristics of Pseudacteon tricuspis Borgmeier (Diptera: Phoridae)," Biological Control, vol. 55, no. 1, pp. 6371, 2010.

[58] B. Hölldobler and E. O. Wilson, The Ants, Harvard University Press, Cambridge, UK, 1990.

[59] P. J. Folgarait, O. A. Bruzzone, and L. E. Gilbert, "Seasonal patterns of activity among species of black fire ant parasitoid flies (Pseudacteon: Phoridae) in Argentina explained by analysis of climatic variables," Biological Control, vol. 28, no. 3, pp. 368-378, 2003.

[60] L. Chen, E. O. Onagbola, and H. Y. Fadamiro, "Effects of temperature, sugar availability, gender, mating, and size on the longevity of phorid fly Pseudacteon tricuspis (Diptera: Phoridae)," Environmental Entomology, vol. 34, no. 2, pp. 246-255, 2005.

[61] E. G. LeBrun, R. M. Plowes, and L. E. Gilbert, "Dynamic expansion in recently introduced populations of fire ant parasitoids (Diptera: Phoridae)," Biological Invasions, vol. 10, no. 7, pp. 989-999, 2008.

[62] L. W. Buss, "Competitive intransitivity and size-frequency distributions of interacting populations," Proceedings of the National Academy of Sciences of the United States of America, vol. 77, no. 9, pp. 5355-5359, 1980.
[63] J. Huisman, A. M. Johansson, E. O. Folmer, and F. J. Weissing, "Towards a solution of the plankton paradox: the importance of physiology and life history," Ecology Letters, vol. 4, no. 5, pp. 408-411, 2001.

[64] B. Kerr, M. A. Riley, M. W. Feldman, and B. J. M. Bohannan, "Local dispersal promotes biodiversity in a real-life game of rock-paper-scissors," Nature, vol. 418, no. 6894, pp. 171-174, 2002.

[65] R. A. Laird and B. S. Schamp, "Does local competition increase the coexistence of species in intransitive networks?" Ecology, vol. 89, no. 1, pp. 237-247, 2008.

[66] J. Rojas-Echenique and S. Allesina, "Interaction rules affect species coexistence in intransitive networks," Ecology, vol. 92, no. 5, pp. 1174-1180, 2011.

[67] J. Vandermeer and S. Yitbarek, "Self-organized spatial pattern determines biodiversity in spatial competition," Journal of Theoretical Biology, vol. 300, no. 1, pp. 48-56, 2012.

[68] D. W. Davidson, "An experimental study of diffuse competition in harvester ants," American Naturalist, vol. 125, no. 4, pp. 500-506, 1985.

[69] J. H. Fellers, "Interference and exploitation in a guild of woodland ants," Ecology, vol. 68, no. 5, pp. 1466-1478, 1987.

[70] J. M. Herbers, "Community structure in north temperate ants: temporal and spatial variation," Oecologia, vol. 81, no. 2, pp. 201-211, 1989.

[71] A. N. Andersen and A. D. Patel, "Meat ants as dominant members of Australian ant communities: an experimental test of their influence on the foraging success and forage abundance of other species," Oecologia, vol. 98, no. 1, pp. 1524, 1994.

[72] I. Perfecto, "Foraging behavior as a determinant of asymmetric competitive interaction between two ant species in a tropical agroecosystem," Oecologia, vol. 98, no. 2, pp. 184192, 1994.

[73] K. G. Human and D. M. Gordon, "Exploitation and interference competition between the invasive Argentine ant, Linepithema humile, and native ant species," Oecologia, vol. 105, no. 3, pp. 405-412, 1996.

[74] I. Perfecto and J. Vandermeer, "Microclimatic changes and the indirect loss of ant diversity in a tropical agroecosystem," Oecologia, vol. 108, no. 3, pp. 577-582, 1996.

[75] N. J. Sanders and D. M. Gordon, "Resource-dependent interactions and the organization of desert ant communities," Ecology, vol. 84, no. 4, pp. 1024-1031, 2003.

[76] C. L. Parr, B. J. Sinclair, A. N. Andersen, K. J. Gaston, and S. L. Chown, "Constraint and competition in assemblages: a cross-continental and modeling approach for ants," American Naturalist, vol. 165, no. 4, pp. 481-494, 2005.

[77] B. T. Bestelmeyer, "The trade-off between thermal tolerance and behavioural dominance in a subtropical South American ant community," Journal of Animal Ecology, vol. 69, no. 6, pp. 998-1009, 2000.

[78] T. M. Palmer, T. P. Young, M. L. Stanton, and E. Wenk, "Short-term dynamics of an acacia ant community in Laikipia, Kenya," Oecologia, vol. 123, no. 3, pp. 425-435, 2000.

[79] X. Cerdá, J. Retana, and S. Cros, "Thermal disruption of transitive hierarchies in Mediterranean ant communities," Journal of Animal Ecology, vol. 66, no. 3, pp. 363-374, 1997.

[80] M. Kaspari, "Worker size and seed size selection by harvester ants in a Neotropical forest," Oecologia, vol. 105, no. 3, pp. 397-404, 1996.

[81] X. Cerdá, J. Retana, and S. Cros, "Critical thermal limits in Mediterranean ant species: trade-off between mortality risk 
and foraging performance," Functional Ecology, vol. 12, no. 1, pp. 45-55, 1998.

[82] L. W. Morrison, "Community organization in a recently assembled fauna: the case of Polynesian ants," Oecologia, vol. 107, no. 2, pp. 243-256, 1996.

[83] D. A. Holway, "Competitive mechanisms underlying the displacement of native ants by the invasive Argentine ant," Ecology, vol. 80, no. 1, pp. 238-251, 1999.

[84] L. Lach, "Interference and exploitation competition of three nectar-thieving invasive ant species," Insectes Sociaux, vol. 52, no. 3, pp. 257-262, 2005.

[85] E. G. Lebrun and D. H. Feener Jr., "When trade-offs interact: balance of terror enforces dominance discovery trade-off in a local ant assemblage," Journal of Animal Ecology, vol. 76, no. 1, pp. 58-64, 2007.

[86] E. G. LeBrun, C. V. Tillberg, A. V. Suarez, P. J. Folgarait, C. R. Smith, and D. A. Holway, "An experimental study of competition between fire ants and Argentine ants in their native range," Ecology, vol. 88, no. 1, pp. 63-75, 2007.

[87] L. A. Calcaterra, J. P. Livore, A. Delgado, and J. A. Briano, "Ecological dominance of the red imported fire ant, Solenopsis invicta, in its native range," Oecologia, vol. 156, no. 2, pp. 411-421, 2008.

[88] D. Tilman, "Competition and biodiversity in spatially structured habitats," Ecology, vol. 75, no. 1, pp. 2-16, 1994.

[89] F. R. Adler and J. Mosquera Losada, "Super- and coinfection: filling the range," in Adaptive Dynamics of Infectious Diseases: In Pursuit of Virulence Management, U. Dieckmann, J. A. J. Metz, M. W. Sabelis, and K. Sigmund, Eds., Cambridge Studies in Adaptive Dynamics, pp. 138-149, Cambridge University Press, Cambridge, UK, 2002.

[90] F. R. Adler, E. G. LeBrun, and D. H. Feener Jr., "Maintaining diversity in an ant community: modeling, extending, and testing the dominance-discovery trade-off," American Naturalist, vol. 169, no. 3, pp. 323-333, 2007.

[91] P. J. Folgarait, "Ant biodiversity and its relationship to ecosystem functioning: a review," Biodiversity and Conservation, vol. 7, no. 9, pp. 1221-1244, 1998.

[92] J. Vandermeer and I. Perfecto, "The diverse faces of ecosystem engineers in agroecosystems," in Ecosystems Engineers-Plants to Protists, K. Cuddington, J. E. Byers, W. G. Wilson, and A. Hastings, Eds., pp. 367-385, Academic Press, Elsevier, New York, NY, USA, 2007.

[93] L. Lach, C. L. Parr, and K. L. Abbott, Ant Ecology, Oxford University Press, Oxford, UK, 2010.

[94] W. W. Kempf, "A study of some Neotropical ants of genus Pheidole Westwood. I. (Hymenoptera: Formicidae)," Studia Entomologica, vol. 15, pp. 449-464, 1972.

[95] J. Vandermeer, I. Perfecto, and S. M. Philpott, "Clusters of ant colonies and robust criticality in a tropical agroecosystem," Nature, vol. 451, no. 7177, pp. 457-459, 2008.

[96] J. Vandermeer and I. Perfecto, "A keystone mutualism drives pattern in a power function," Science, vol. 311, no. 5763, pp. 1000-1002, 2006.

[97] J. Vandermeer, I. Perfecto, G. Ibarra Nuñez, S. Phillpott, and A. Garcia Ballinas, "Ants (Azteca sp.) as potential biological control agents in shade coffee production in Chiapas, Mexico," Agroforestry Systems, vol. 56, no. 3, pp. 271-276, 2002.

[98] A. de la Mora, G. Livingston, and S. M. Philpott, "Arboreal ant abundance and leaf miner damage in coffee agroecosystems in Mexico," Biotropica, vol. 40, no. 6, pp. 742-746, 2008.

[99] D. J. Gonthier, G. L. Pardee, and S. M. Philpott, "Azteca instabilis ants and the defence of a coffee shade tree: an ant-plant association without mutual rewards in Chiapas, Mexico," Journal of Tropical Ecology, vol. 26, no. 3, pp. 343346, 2010.

[100] G. L. Pardee and S. M. Philpott, "Cascading indirect effects in a coffee agroecosystem: effects of parasitic phorid flies on ants and the coffee berry borer in a high-shade and low-shade habitat," Environmental Entomology, vol. 40, no. 3, pp. 581588, 2011.

[101] I. Perfecto and J. Vandermeer, "Spatial pattern and ecological process in the coffee agroforestry system," Ecology, vol. 89, no. 4, pp. 915-920, 2008.

[102] D. Jackson, J. Vandermeer, and I. Perfecto, "Spatial and temporal dynamics of a fungal pathogen promote pattern formation in a tropical agroecosystem," The Open Ecology Journal, vol. 2, pp. 62-73, 2009.

[103] J. Vandermeer, I. Perfecto, and H. Liere, "Evidence for hyperparasitism of coffee rust (Hemileia vastatrix) by the entomogenous fungus, Lecanicillium lecanii, through a complex ecological web," Plant Pathology, vol. 58, no. 4, pp. 636641, 2009.

[104] S. M. Philpott, "A canopy dominant ant affects twig-nesting ant assembly in coffee agroecosystems," Oikos, vol. 119, no. 12, pp. 1954-1960, 2010.

[105] B. V. Brown and S. M. Philpott, "Pseudacteon parasitoids of Azteca instabilis ants in Southern Mexico (Diptera: Phoridae, Hymenoptera: Formicidae)," Psyche, vol. 2012, Article ID 351232, 2012.

[106] H. Liere and I. Perfecto, "Cheating on a mutualism: indirect benefits of ant attendance to a coccidophagous coccinellid," Environmental Entomology, vol. 37, no. 1, pp. 143-149, 2008.

[107] M. P. Hassell, H. N. Comins, and R. M. May, "Spatial structure and chaos in insect population dynamics," Nature, vol. 353, no. 6341, pp. 255-258, 1991. 

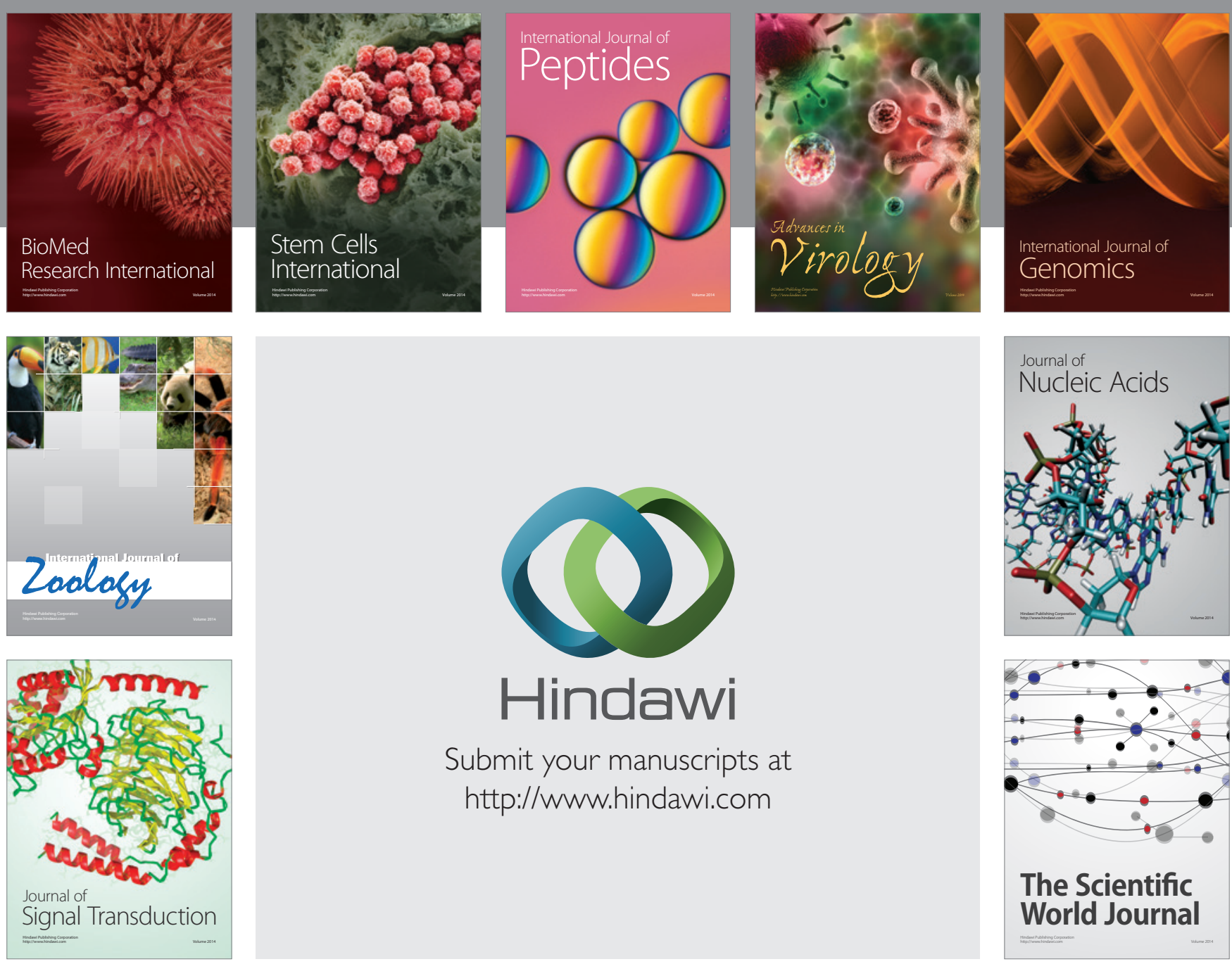

Submit your manuscripts at

http://www.hindawi.com
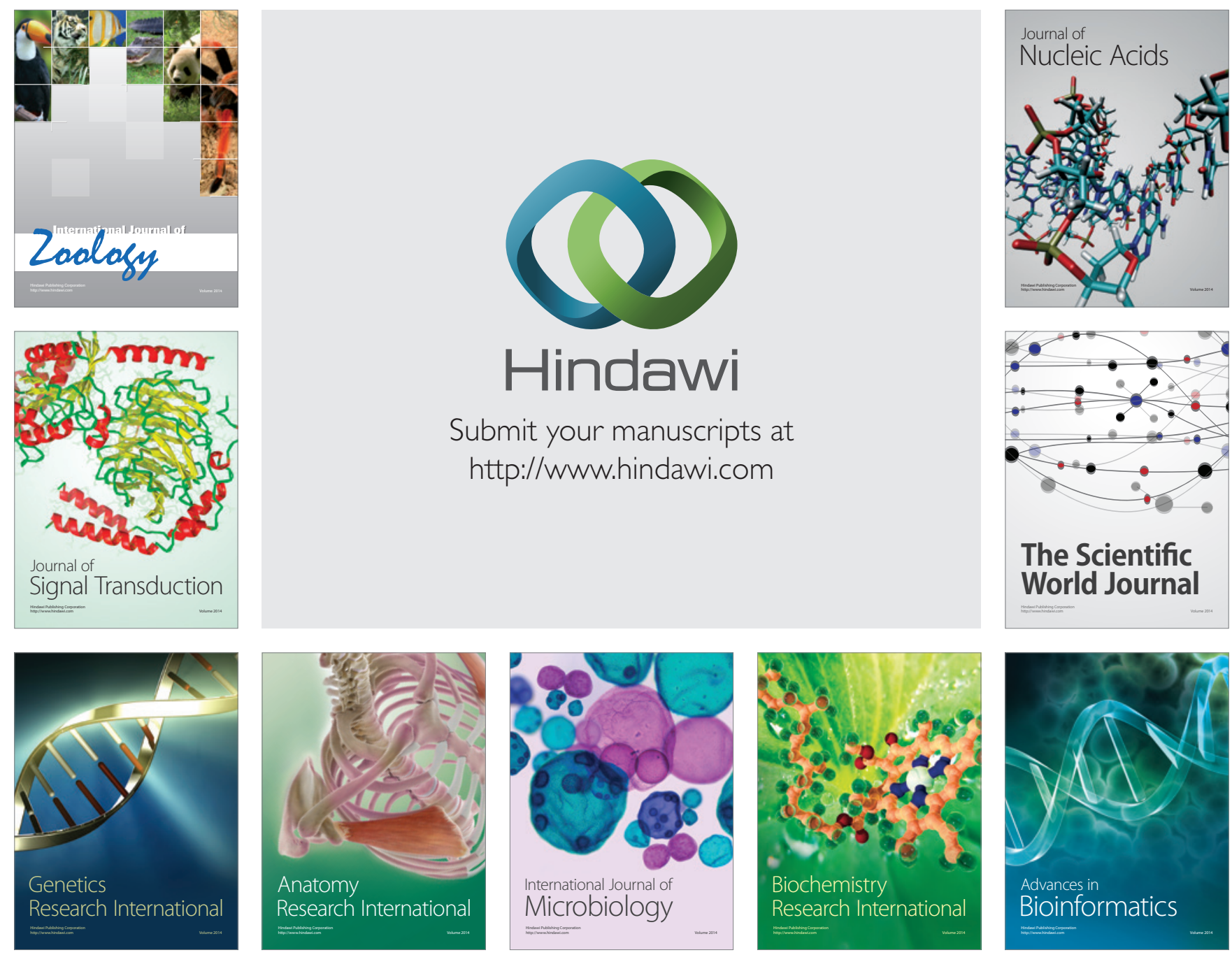

The Scientific World Journal
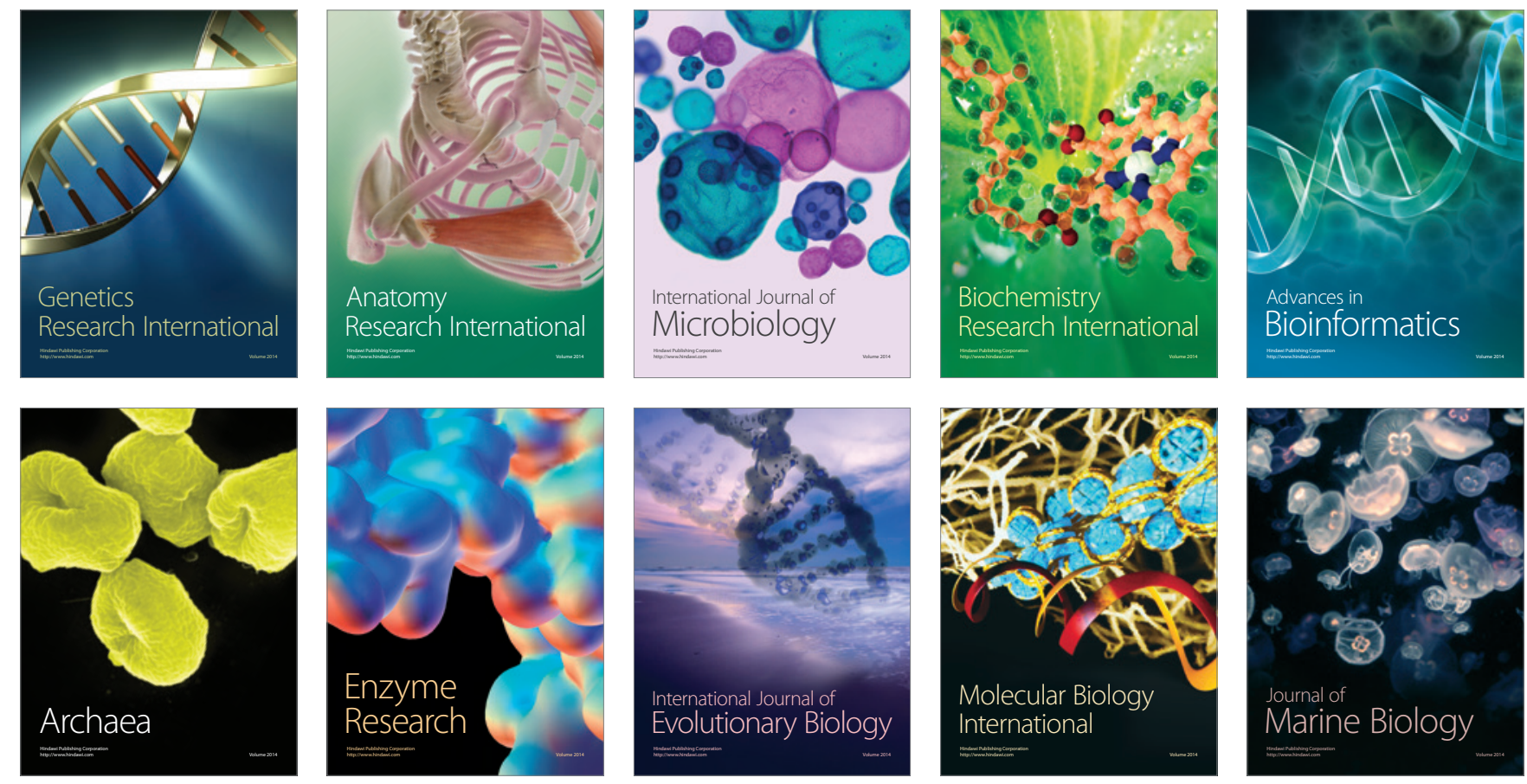